\title{
Evaluation for the Service Quality of Exhibitions --A Case Study of Tianjin Home Expo
}

\author{
Lu Zhang \\ Wuhan University of Technology, Wuhan, 430070, China \\ zhangluhuizhan@126.com
}

\begin{abstract}
The convention and exhibition industry is an emerging service industry, whose service quality has become an important factor affecting its development. Firstly, based on the SEVEQUAL model, this paper designs a survey scale for service quality from dimensions of tangibles, reliability, responsiveness, assurance and empathy in line with characteristics of exhibitions. Then, taking the Tianjin Home Expo as an example, this study calculates the comprehensive score of service quality with methods of questionnaire investigation and empirical analysis, and concludes several problems of the service quality existing in the exhibition through analyzing and comparing gaps between visitors' expectations and actual perceptions, and raises a few concrete measures and suggestions.
\end{abstract}

Keywords: Exhibition; Service quality; SERVQUAL model; Tianjin Home Expo.

\section{Introduction}

Convention and exhibition is a general term for meetings, exhibitions, incentive travels and festival activities, which has "three high" characteristics, that is, high professional, high concentration and high promotion. It has great driving effect on the related industries like catering, accommodation, tourism, logistics, advertising, etc. Generally speaking, the ratio that the convention and exhibition industry drives the related industries is 1:10. As an emerging service industry, the promotion of the exhibition service is a competitive edge of the exhibition. High quality exhibition services can attract more audience to participate in the exhibition, bring more customers for exhibitors and thus attract more high-quality exhibitors to the exhibition, and high quality exhibitors in turn attract more audience, so how to evaluate the service quality of the convention and exhibition industry and raise some effective suggestions have become an important topic in current academic circles.

There are many academic researches about the service quality of exhibitions. From the perspective of service, Breiter and Milman (2006) explore the different needs of the participants and the different degree of attention on services [1]. Yuanyuan Kang (2011) measures the exhibitors' satisfaction with the exhibition hall service by a single project, thereby measuring the relationship between service and satisfaction [2]. Zhang Tao (2011) constructs the satisfaction index model and evaluation index system of exhibition service [3]. Taking Canton Fair as an example, Huizhen Jin and Pang Hua (2015) build the exhibition service quality evaluation system from five dimensions of hardware facilities services, professional services, supporting services, on-site service and post service [4].

\section{Model Selection and Index Design}

\subsection{SERVQUAL MODEL}

The SERVQUAL model is a classical model of questionnaire evaluation system of service quality for the customer. It evaluates the quality of the service from five dimensions: tangibles, reliability, responsiveness, assurance and empathy, and finds out the gaps of service quality through customers' service expectations and perceptions. The SERVQUAL model is expressed as:

$$
\mathrm{SQ}=\left[\sum_{\mathrm{i}=1}^{\mathrm{n}}\left(\mathrm{P}_{\mathrm{i}}-\mathrm{E}_{\mathrm{i}}\right)\right] / \mathrm{n}
$$

Among them, SQ is the overall score of the service quality of the organization, $\mathrm{E}_{\mathrm{i}}$ is the customer's expectation score of the question $\mathrm{I}, \mathrm{P}_{\mathrm{i}}$ is customer's actual perception score of the question $\mathrm{I} ; \mathrm{n}$ is the 
total number of indicators. When $\mathrm{P}_{\mathrm{i}}>\mathrm{E}_{\mathrm{i}}$, customer's perceived value of the service is greater than expected value, that means the performance is very satisfying. When $\mathrm{P}_{\mathrm{i}}=\mathrm{E}_{\mathrm{i}}$, customer's perceived value of the service is equal to expected value, the performance is basically satisfactory. When $\mathrm{P}_{\mathrm{i}}<\mathrm{E}_{\mathrm{i}}$, customer's perceived value of the service is less than their expected value, which means the performance is not satisfying.

\subsection{Index Design}

Based on the SERVQUAL model, this paper designs a set of service quality evaluation index system covering 1 first class indicator, 5 second class indicators and 20 third class indicators, as shown in table 1.

Table 1 Indicators of service quality of exhibition based on SERVQUAL model

\begin{tabular}{|c|c|c|}
\hline $\begin{array}{l}\text { First Class } \\
\text { Indicator }\end{array}$ & $\begin{array}{l}\text { Second Class } \\
\text { Indicators }\end{array}$ & Third Class Indicators \\
\hline $\begin{array}{l}\text { Service } \\
\text { quality of } \\
\text { the } \\
\text { exhibition }\end{array}$ & Responsiveness & $\begin{array}{l}\text { A1.The appearance of the physical facilities is modern } \\
\text { A2. The layout of the booth is reasonable } \\
\text { A3. The constructions of the booth are attractive } \\
\text { A4. The scale of the exhibition is large } \\
\text { B1. The environment of the exhibition is safe } \\
\text { B2. The information of propaganda is comprehensive } \\
\text { B3. The styles of propaganda are diverse } \\
\text { B4. The promise can be completed in time } \\
\text { C1. Services that are reliable and convenient } \\
\text { C2. The service is initiative } \\
\text { C3. The service is immediate } \\
\text { C4. The service attitude is cordial } \\
\text { C5. The service is timely } \\
\text { D1. The exhibitors have high visibility } \\
\text { D2. The exhibitors have good credibility } \\
\text { D3. The number of exhibitors is suitable } \\
\text { D4. The transactions are reassuring } \\
\text { E1. Understand visitors' needs initiatively } \\
\text { E2. Consider visitors' benefits first } \\
\text { E3. The number of activities visitors can participate is high }\end{array}$ \\
\hline
\end{tabular}

\section{Empirical analysis}

\subsection{Research object and data sources}

This study takes the Tianjin Home Expo as an example and setts visitors as the objects of the research. The Tianjin Home Expo is a sub-station of the Huaxia Home Expo, which is the most authoritative Home Expo of China. It's a highly specialized exhibition with about 1500 booths, nearly 30,000 square meters of exhibition areas and a large number of visitors, so it has a high representative for the exhibition industry.

This study collects the data with method of questionnaire investigation. 310 questionnaires were delivered and 272 valid questionnaires were taken back. The valid recovery rate is $87.7 \%$.

\subsection{The empirical result analysis}

To calculate the score of exhibition's service quality, options of every indicator in the questionnaire are assigned. A stands for 5 points, $\mathrm{B}$ for 4 points, $\mathrm{C}$ for 3 points, $\mathrm{D}$ for 2 points, $\mathrm{E}$ for 1 points. By calculating the available data, this paper obtains the result of visitors' expectations and perceptions.

The overall service quality of Tianjin Home Expo can be calculated without considering the dimensions of the weights, that is, $\mathrm{SQ}=-0.31$.To compare and analyze the result more easily, percentile $\mathrm{SQ}$ algorithm $(0 \leq \mathrm{SQ} \leq 100)$ is introduced. The equation is 


$$
\mathrm{SQ}_{p}=\frac{S Q-[\min (P)-\max (E)]}{0-[\min (P)-\max (E)]} \times 100
$$

Where SQ is the initial score of service quality; SQP is the score of service quality after the conversion of percentile; min $(\mathrm{P})$ is the minimum value of the perception; max $(\mathrm{E})$ is the maximum value of the expectation.

Using the equation (2), we can calculate that the score of the Tianjin Home Expo's service quality is 78.1 points, which is in the middle level. The result reveals that the service quality of the Tianjin Home Expo still needs to be further improved.

\subsection{Existing Problems}

According to the result of the empirical analysis in table 2, from the overall perspective, the satisfaction of visitors to the Tianjin Home Expo is a little low. The value of perception of each indicator is lower than that of the value of expectation; the comprehensive score is 78.1 points; the sequence of values for the gap of service quality arranged in descending order is tangibles > empathy $>$ assurance $=$ responsiveness $>$ reliability, which is shown in figure 1 and from the perspective of five dimensions, problems are as follows:

Table 2 Service quality distance between visitors' expectations and perceptions

\begin{tabular}{|c|c|c|c|c|}
\hline Dimensions & indicators & $\begin{array}{c}\text { mean of } \\
\text { expectation } \\
\text { Ei }\end{array}$ & $\begin{array}{c}\text { mean of } \\
\text { perception } \\
\mathrm{Pi}\end{array}$ & SQ \\
\hline \multirow{5}{*}{ Tangibles } & $\begin{array}{l}\text { A1.The appearance of the physical facilities is } \\
\text { modern }\end{array}$ & 3.88 & 3.68 & -0.20 \\
\hline & A2. The layout of the booth is reasonable & 3.84 & 3.12 & -0.72 \\
\hline & A3. The constructions of booths are attractive & 3.78 & 3.42 & -0.36 \\
\hline & A4. The scale of the exhibition is large & 4.07 & 3.49 & -0.58 \\
\hline & Mean value & 3.89 & 3.43 & -0.46 \\
\hline \multirow{5}{*}{ Reliability } & B1. The environment of the exhibition is safe & 3.79 & 3.58 & -0.21 \\
\hline & $\begin{array}{l}\text { B2. The information of propaganda is } \\
\text { comprehensive }\end{array}$ & 3.76 & 3.30 & -0.46 \\
\hline & B3. The styles of propaganda are diverse & 3.95 & 3.91 & -0.04 \\
\hline & B4. The promise can be completed in time & 4.07 & 3.96 & -0.11 \\
\hline & Mean value & 3.89 & 3.69 & -0.20 \\
\hline \multirow{6}{*}{$\begin{array}{l}\text { Responsive } \\
\text {-ness }\end{array}$} & $\begin{array}{l}\text { C1. Catering, logistics, and other additional } \\
\text { services are reliable and convenient }\end{array}$ & 4.01 & 3.37 & -0.64 \\
\hline & $\mathrm{C} 2$. The service is initiative & 3.95 & 3.47 & -0.48 \\
\hline & $\mathrm{C} 3$. The service is immediate & 4.20 & 4.05 & -0.15 \\
\hline & $\mathrm{C} 4$. The service attitude is cordial & 4.13 & 4.01 & -0.12 \\
\hline & C5. The service is timely & 4.55 & 4.47 & -0.08 \\
\hline & Mean value & 4.17 & 3.87 & -0.30 \\
\hline \multirow{5}{*}{ Assurance } & D1. The exhibitors have high visibility & 3.82 & 3.54 & -0.28 \\
\hline & D2. The exhibitors have good credibility & 4.05 & 3.96 & -0.09 \\
\hline & D3. The number of exhibitors is suitable & 3.95 & 3.37 & -0.58 \\
\hline & D4. The transactions are reassuring & 4.01 & 3.78 & -0.23 \\
\hline & Mean value & 3.96 & 3.66 & -0.30 \\
\hline \multirow{4}{*}{ Empathy } & E1. Understand visitors' needs initiatively & 3.86 & 3.32 & -0.54 \\
\hline & E2. Consider visitors' benefits first & 4.11 & 4.01 & -0.10 \\
\hline & $\begin{array}{l}\text { E3. The number of activities that visitors can } \\
\text { participate in is suitable }\end{array}$ & 3.63 & 3.25 & -0.38 \\
\hline & Mean value & 3.87 & 3.53 & -0.34 \\
\hline
\end{tabular}




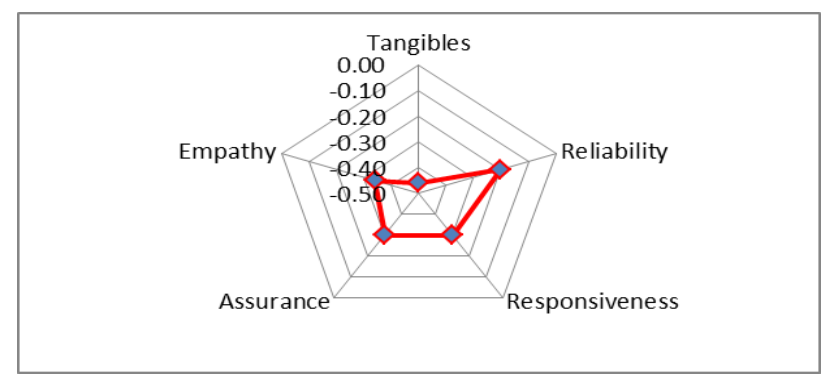

Figure 1 The gap of service quality in the Tianjin Home Expo

(1) Tangible: the construction of the booth is unattractive; the layout of the booth isn't reasonable, and the scale of the exhibition is small. The most satisfactory indicator to visitors is the modern physical facilities. The difference between the value of perception and the value of the expectation is very low, only -0.2 .The difference in the aspect of the construction of the booth is -0.36 , and in terms of the layout of the booth and the scale of the exhibition, the differences are very high, -0.72 and -0.58 , respectively, meaning the service quality of these two aspects need to be improved to a great degree.

(2) Reliability: the information of propaganda isn't very comprehensive and the environment of the exhibition isn't very safe. Visitors have higher satisfaction to two indicators: the styles of propaganda are diverse and the promise can be completed in time. The differences between the value of the perception and the value of the expectation in these two aspects are very low, -0.04 and -0.07 , respectively. For the safety of the exhibition's environment, the difference is -0.21 , a bit low, and for the comprehensiveness of the information of the propaganda, the difference is -0.46 , a bit high.

(3) Responsiveness: Catering, logistics, and other additional services aren't very reliable and convenient and the service isn't very initiative. For the last three indicators: the service is immediate; the service attitude is cordial, and the service is timely, visitors have high satisfaction. The differences between the value of the perception and the value of the expectation are $-0.15,-0.12$ and -0.08 , respectively. However, for the initiation of the services and the reliability and convenience of additional services, the differences are -0.48 and -0.64 , respectively, a bit high.

(4) Assurance: The number of exhibitors is a little small and the visibility of exhibitors is a bit low. For the indicators that the exhibitors have good credibility and the transactions are reassuring, visitors have high satisfaction. The differences between the value of the perception and the value of the expectation are -0.09 and -0.23 , respectively. However, for exhibitors' visibility and quantity, visitors' are not very satisfactory, the differences are -0.28 and -0.58 , respectively.

(5) Empathy: service staffs are not very initiative in terms of understanding visitors' needs; the quantity of activities that visitors can participate in is not very much. For the indicators that the service staffs consider visitors' benefits first, visitors' satisfaction are highest, the differences between the value of the perception and the value of the expectation is -0.1 , which is very low. For the indicators that service staffs can understand visitors' needs initiatively and the number of activities that visitors can participate in is suitable, the differences are a bit high, -0.54 and -0.38 respectively.

\section{Improvement proposals}

(1) Enhance the convenience of other additional services such as catering, logistics, and so on. Firstly, Exhibition organizers should regulate providers' services. It means the logistics company must seriously take their work, like transporting exhibits, storing and handling of exhibits and other aspects of the work so that unnecessarily damages or losses of exhibits can be avoided to the visitors. Secondly, Exhibition organizers should choose providers of exhibition tourism service with high quality and high reputation because they directly contact with visitors.

(2) Expand the scale of the exhibition and improve the layout of the booth. Firstly, Exhibition organizers should have the conscious of reducing the cost of the exhibition. For example, they can take some measures to reduce unnecessary propaganda and modern equipment and facilities. Secondly, they can also consider enhancing the income of the exhibition by improving the number and quality of exhibitors and attract more professional visitors. For the layout of the booth, organizers 
may consider designing it based on the characteristics of exhibition center and take all factors, such as service objectives, space needs, safety factors, aesthetic factors and human engineering into account.

(3) Enhance the initiative service and carry out personalized service. Firstly, strengthen the training of staff's professional service and active service consciousness is a good way to achieve this goal. Secondly, service performance evaluation mechanism should be improved. Hooking the staff's performance and customer satisfaction can increase their job satisfaction in some extend. Thirdly, in order to take the initiative to understand the needs of the audience, exhibition organizer should investigate the needs of the audience by means of a questionnaire or a visit during the exhibition. Finally, activities that more visitors can participate in should be increased by the host through the means of prize draw, quizzing, building the audience experience service platform and so on.

(4) Pay attention to the comprehensiveness of the publicity information, and increase the number of well-known exhibitors. Firstly, publicity information should include the time, venue, display range, traffic routes exhibitors, sponsors and other auxiliary information. Secondly, exhibition organizers should select the appropriate channels to enhance the effectiveness of the exhibition publicity to attract more exhibitors, thereby attracting more exhibitors. Thirdly, select exhibitors with high visibility and great credit.

\section{Conclusion}

This study shows that improving the service quality is the main way to promote the development of exhibition industry. Based on the SEVEQUAL theory, the paper designs a set of service quality scale in line with the characteristics of the Tianjin Home Expo. Setting visitors as the research objects, this study measures the service quality of the Tianjin Home Expo from five dimensions, tangibles, reliability, responsiveness, assurance and empathy and then makes a conclusion: the sequence of values for service quality gap arranged in descending order is tangibles $>$ empathy $>$ assurance $=$ responsiveness > reliability and the percentile score of SQ is 78.1 points, which is at a medium level. Through the analysis and comparison of gaps between visitors' expectations and actual perceptions, the author finds that several problems of the service quality are supposed to exist in the Tianjin home expo and put forward concrete measures and suggestions.

\section{Acknowledgments}

This paper is supported by National Science Foundation of China (71373199), the Fundamental Research Funds for the Central Universities (2016VI027) and the Soft Science of Wuhan (201604030610181).

\section{References}

[1] Breiter D, Milman A Attendens'needs and service priorities in a large convention center based on the importance-performance theory. Tourism Management. Vol. 27(2006) No. 6, P. 1364-1370.

[2] Yuanyuan Kang. An empirical study of satisfaction on the venue's assistant facilities and services (Management, East China Normal University, China 2011). p. 37-59.

[3] Tao Zhang. Research on the satisfaction evaluation of exhibition service -- a case study of Macao international trade and Investment Exhibition. Tourism Forum. Vol. 04(2011) No.1, P. 36-41.

[4] Huizhen Jin, Hua Pang. Discussion on the service quality of the exhibition -- a case study of Guangzhou Fair. Journal of Changchun Normal University. Vol.34 (2015) No. 1, P. 22-24. 